\title{
The study of phenolics content in the emblica fruit wine
}

\author{
Minjie Li, Ya Xiong \\ Department of Biological and Chemical Engineering, Panzhihua University, Panzhihua 617000, China
}

\begin{abstract}
Emblic fruit wine rich in alcohol, phenolics. This experiment adopts the reverse high performance liquid chromatography (HPLC) method for emblic leafflower fruit wine representative of phenolics gallic acid, quercetin content determination of study; And the emblic leafflower fruit forint phenol method study on determination of total phenol content in fruit wine. Experimental results show that the forint phenol method is used to measure total phenolic content (with gallic acid) in the range of 1-6 ug/ml has good linear relation, measured over the basic total phenol content in fruit wine was $4.6 \mathrm{mg} / \mathrm{ml}$; Reverse high performance liquid chromatography (HPLC) method to measure content of gallic acid, quercetin in 8-400 ug/ml has good linear relation, measured over the basic content of gallic acid in fruit wine was $0.82 \mathrm{mg} / \mathrm{ml}$, quercetin is 0.94 $\mathrm{ug} / \mathrm{ml}$.
\end{abstract}

KEYWORD: RP-HPLC, Phyllanthus emblica, wine, gallic acid, quercetin

\section{INTRODUCTION}

Emblic fruit of Euphorbiaceae (Euphorbiaceae) leaf under bead (Phyllanthus) tropical, subtropical deciduous fruits of small trees. Emblic fruit fruit contain a variety of nutrients, such as polyphenols, organic acids, vitamins, sugars, amino acids and other substances and trace elements $\mathrm{Fe}, \mathrm{Mn}$, zinc, $\mathrm{Ca}$, Se and so on. Emblic fruit fruit of phenolic acids, flavonoids and other polyphenols and saccharide substances, content is very rich, and wild varieties of active material content is much higher than cultivated. With active substances such as data showed that have good ability of scavenging free radicals and the oxidation resistance ability, fall hematic fat, fall blood pressure, anti-tumor, prevention of atherosclerosis, enhance immunity, anti-inflammatory analgesic has certain effect. Representative material of gallic acid, also known as "gallic acid", is the nature of polyphenol compounds, in food, biology, medicine, chemical industry has a very wide application. Gallic acid has anti-inflammatory, antioxidant, anti mutation and fight free radicals and other biological activities; In addition, the gallic acid also has antitumor effect, can inhibit mast cell tumor metastasis to prolong survival time. Also make better kill trypan drug candidates; Have the effect that protect liver, can resist carbon tetrachloride induced liver physiological and biochemical changes.

This subject is the basic content of reverse high performance liquid chromatography (HPLC) method is used to determine the emblic fruit wine of gallic acid and the content of quercetin in emblic fruit wine with the forint phenol method, the content of total phenolics, provide a basis for the study of the emblic fruit's nutritional value, help to improve the quality of fruit wine and fruit juice.

\section{EXPERIMENT}

\subsection{Materials and eqipments.}

Raw materials: the Emblic fruit wine is from Renhe county of Panzhihua.

Equipments: electronic balance FA2104S; ultraviolet spectrophotometer L5; ultrapure water machine UPK-L-10T;HPLC 1200

\subsection{Methods of experiments.}

Determination of total phenolic.

Configuration of the standard solution: accurate said $0.005 \mathrm{~g}$ gallic acid standard, ultrapure water constant volume to $50 \mathrm{ml}$, gallic acid standard solution concentration is $0.1 \mathrm{mg} / \mathrm{ml}$.

The establishment of the standard curve: use pipette accurately measuring the solution above $0,0.5$, $1.0,1.5,2.0,1.5,2.0 \mathrm{ml}$ in $50 \mathrm{ml}$ volumetric flask and add $30 \mathrm{ml}$ deionized water, shake well, add 2.5 $\mathrm{ml}$ forint reagent, fully shake, 1 minutes after add $8.0 \mathrm{ml} 9 \%$ sodium carbonate solution, blending the 
capacity. Water bath reaction under 66 degrees Celsius for 10 minutes, $760 \mathrm{~nm}$ wavelength determination of absorbance, establish standard curve.

Sample measurement: precision measuring preparation good emblic leafflower fruit wine sample solution $0.5 \mathrm{ml}$ in $50 \mathrm{ml}$ volumetric flask and add 30 $\mathrm{ml}$ deionized water, shake well, add $2.5 \mathrm{ml}$ forint phenol reagent, $8.0 \mathrm{ml} 9 \%$ sodium carbonate solution, constant volume, deionized water and mixed water bath reaction under 66 degrees Celsius, 10 minutes after cooling determine its absorbance at $760 \mathrm{~nm}$.

Stability testing: accurate said emblic leafflower fruit wine sample solution $0.5 \mathrm{ml}$, according to the measuring method, placed at room temperature 0,1 , $2,3,4,5,6,7,8,9 \mathrm{~h}$ measuring absorbance value, to determine the stability of the forint phenol method. If the absorbance is greater than 1 , dilute solution to be tested again.

Precision of the experiment: accurate said emblic leafflower fruit wine sample solution $0.5 \mathrm{ml}$, according to the measuring method of repeated six times.

Repetitive experiments: accurate said more than 6 basic wine sample solution $0.5 \mathrm{ml}$, respectively, according to the measuring method for determining absorbance values.

Recovery experiment: the content of known emblic leafflower fruit wine sample solution 3 copies of each precise join gallic acid standard solution 0.5 , $1.0,1.5 \mathrm{ml}$, according to the method of measuring method, take the average absorbance value and the total phenol content, calculate the sample recovery rate.

Gallic acid and quercetin

Configuration of the standard solution, precision weigh and gallic acid, respectively $10.0 \mathrm{mg}$ quercetin standard to $25 \mathrm{ml}$ volumetric flask, with $90 \%$ methanol concentration of water soluble solvent configured to $400.0 \mathrm{ug} / \mathrm{ml}$ single standard solution, shake well, set aside.

$25 \mathrm{ml}$ wine extract: take wine, according to the 1:1 ratio to join anhydrous diethyl ether extraction, extraction $3 \mathrm{~min}$, take out ester phase, water phase extraction four times, repeatedly merging ester, less than $35{ }^{\circ} \mathrm{C}$ spin steaming to dry, $260 \mathrm{r} / \mathrm{min}$. Residue is dissolved in $2 \mathrm{ml}$ of $90 \%$ methanol aqueous solution, $0.45 \mathrm{mu} \mathrm{m}$ membrane filter, as the test solution.

Linear range: apply different concentration of standard solution, dilute concentrations were 400.0, 200.0, 80.0, 40.0, 20.0, and $8.0 \mathrm{ug} / \mathrm{ml}$ of gallic acid, quercetin series of six different concentration of standard solution, precision measuring 10.0 ul into the highly effective liquid phase color spectrometer, sample analysis.

Precision experiments: samples from $25 \mathrm{ml}$ wine press wine extraction method, measuring $10 \mathrm{ul} \mathrm{sam-}$ ple analysis, repeated sampling 5 times, by chromatographic peak area observation precision index.
Repetitive experiments: take $20 \mathrm{ml}$ emblic leafflower fruit wine, add $5 \mathrm{ml}$, mixed standard solution preparation, according to the fruit wine extraction method to extract for the test solution, respectively, precision measuring $10 \mathrm{ul}$ into the highly effective liquid phase color spectrometer, sample analysis.

Solution stability experiment: take the same standard solution and let stand at room temperature, respectively, at $0,2,4,6,8,12,24$ hours, measuring 10 ul into the highly effective liquid phase color spectrometer, sample analysis, chromatographic peak area in different time points are calculated separately, and the RSD values, examine the stability of the sample solution.

Content of sample recovery rate experiment: take known emblic leafflower fruit wine solution in 3, 20 $\mathrm{ml}, 5 \mathrm{ml}$ each, respectively, to join the standard solution, preparation of the test solution, measuring $10 \mathrm{ul}$ into the highly effective liquid phase color spectrometer, measuring the recovery rate of the sample.

\section{RESULTS AND ANALYSIS}

\subsection{The establishment of the total phenol standard curve.}

Accurate quantity from $0.1 \mathrm{mg} / \mathrm{ml}$ of gallic acid standard solution $0,0.5,1.0,1.5,2.0,2.5,3.0 \mathrm{ml}$ in $50 \mathrm{ml}$ volumetric flask and add $30 \mathrm{ml}$ deionized water, shake well, add $2.5 \mathrm{ml}$ forint reagent, fully shake, 1 minutes after add $8.0 \mathrm{ml}$ of $9 \%$ sodium carbonate solution, blending the capacity. Water bath reaction under 66 degrees Celsius for 10 minutes, $760 \mathrm{~nm}$ wavelength determination of absorbance, establish standard curve.

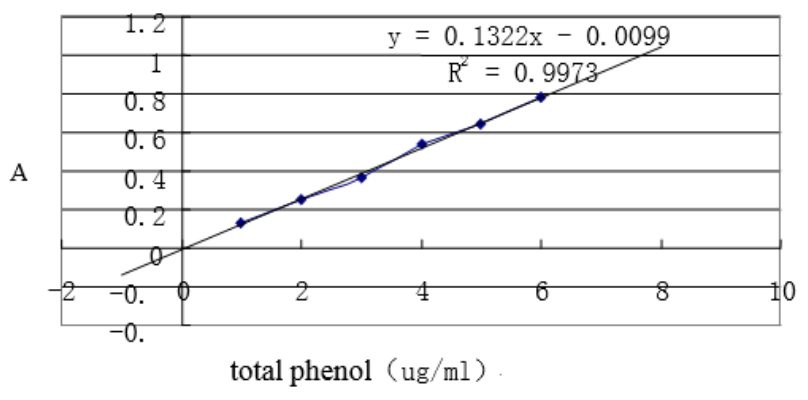

Fig. 1 The standard curve of total phenol

Get regression equation $y=0.1322 x-0.0099, \quad R=0.9973$ 。

\subsection{Used in the determination of total phenol.}

Accurate according to take more than six basic wine sample solution $0.5 \mathrm{ml}$, determine the method were determined respectively in the absorbance values. Take the average of the determination of six times, to the total phenol content in the samples of 0.46 $\mathrm{mg} / \mathrm{ml}$, total phenol content in fruit wine was 4.6 $\mathrm{mg} / \mathrm{ml}$. 


\subsection{The content of gallic acid.}

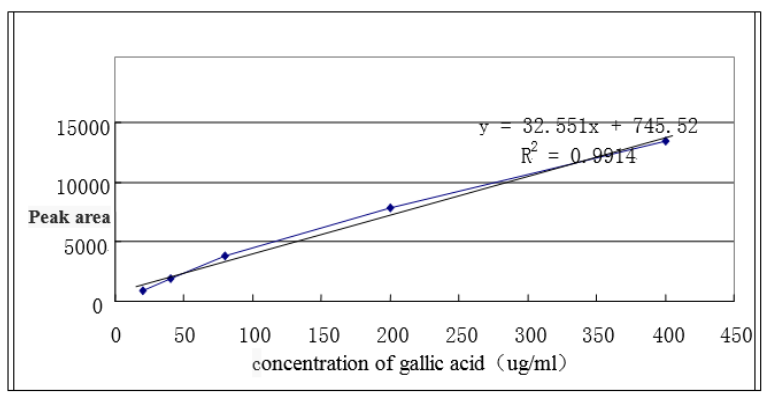

Fig.2 The standard curve of gallic acid Get regression equation $\mathrm{y}=32.551 \mathrm{x}+745.52, \mathrm{R}=0.9914$

Six points measuring $25 \mathrm{ml}$ wine press wine extraction method preparation of samples, 100 times dilution, and measuring 10 ul sample analysis respectively. Determination of average six times, gallic acid content in the samples of $102.66 \mathrm{ug} / \mathrm{ml}$, gallic acid content in fruit wine was $0.82 \mathrm{mg} / \mathrm{ml}$.

\subsection{Quercetin content.}

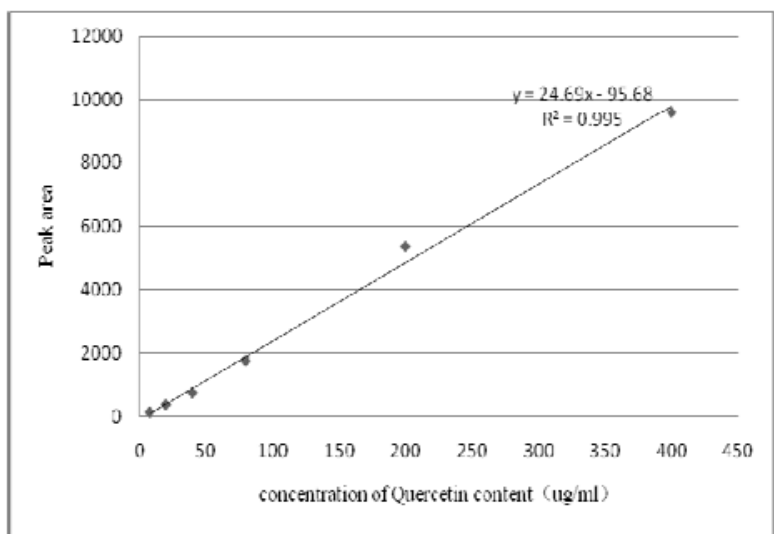

Fig.3 The standard curve of Quercetin content Get regression equation $\mathrm{y}=24.698 \mathrm{x}-95.688, \mathrm{R}=0.9952$

Six points measuring $25 \mathrm{ml}$ wine press wine extraction method preparation of samples, respectively measuring 10 ul sample analysis, samples from six times to determine the average worth of quercetin content is $11.77 \mathrm{ug} / \mathrm{ml}$, quercetin content in fruit wine was $0.94 \mathrm{ug} / \mathrm{ml}$.

\section{SUMMARY}

Material gallic acid and study on determination of quercetin. The difficulties in this part of the experiment is to find the right ratio of mobile phase and separate the components in the samples thoroughly, separating degree greater than 1.5 , and find a suitable detection wavelength, the final experiment determination of gallic acid in the mobile phase (methanol: $0.2 \%$ of phosphoric acid $=5: 95$ ), detection wavelength of $273 \mathrm{~nm}$; Determination of quercetin in the mobile phase (methanol: $0.4 \%$ phosphoric acid $=50: 50$ ), detection wavelength of $360 \mathrm{~nm}$; Ultimately measured over the basic gallic acid content in fruit wine was $0.82 \mathrm{mg} / \mathrm{ml}$, quercetin content is 0.94 ug/ml.

\section{REFERENCES}

Chang nianju, Zhang Zonghe, Huang Jialing et al. The preparation and application of the preparation and application of [J]. Biomass chemical engineering, 2010 ,30(4):75-78.

Cai Yingqing. China emblic germplasm resources exploitation and utilization [J]. Fujian fruits, 2000, 20(1): 13- 18.

Dai Zheng Fu. Emblica in dry hot valley of Jinsha river ecosystem benefit and comprehensive utilization [J]. Tropical crop research, 1990,30(5):107-110.

Song bo. Preparation and application of acid in Hunan [J]. Chemical industry, 1999 , 20(3):14-16.

Wang Shanshan, Wang Yan, Fu Hao. The development of Green Tea emblica instant [J].Beverage industry, 2008 , 22(9):28-33.

Zhang Lanzhen, Guo Yajian. Tibetan medicine Phyllanthus emblica chemical composition [J]. China Journal of Chinese Materia Medica, 2003,28 (10): 94-100.

Zhou Tao, Qiu Devin. Overview of national medicine pharmacy materia medica emblica [J]. Journal of Guiyang College of Traditional Chinese Medicine, 2002,24 (3): 32-37. 